AVRASYA Uluslararası Araştırmalar Dergisi Cilt:5 •Sayı:11•Temmuz 2017•Türkiye

\title{
AZERBAYCAN VE ANADOLU FOLKLORUNDA MEVSIMI OYUN VE TEMAŞALAR
}

Doç.Dr.Meleyke MEMMEDOVA*

\begin{abstract}
öz
Halk oyunlarının kamil ilkin örnekleri ayrı ayrı merasimlerle, özellikle de mevsim merasimleriyle ilgili olmuştur. Halk tarımcılık, çiftçilik hayatı ve doğayla ilgili olan bu oyunlarda her zaman bolluk arzulamış, mevsimleri övmüş, onların gelişini şarkılarla, danslarla, oyun ve temaşalarla karşılamıştır. Çeşitli inançlarla, hayat tarzı, emek faaliyetiyle ilgili oyunlar içinde mevsimi oyunlar yağmur yağdırmak, yağmuru kesmek, güneşi çağırmak, ateşi tutuşturmak, rüzgarı çağırmak, rüzgarı durdurmak gibi işlemleri yerine yetirmek için oynanılmıştır. Bu tür oyunlarda taş kitabelere kazınmış ve Türk halklarının bize gelip ulaşmış en eski oyunları olan, sonralar milli danslarda, halaylarda, çeşitli oyun ve temaşalarda kendine yer edinmiş "dansiçi oyunların" dans unsurları ve eski Türk inançlarının izleri korunmuştur.

Mevsimi oyunlar genellikle bağbozumu, hasat, çeşitli bayram temizlikleri zamanı ve çeşitli mevsimlerle - ilkbahar, yaz, sonbahar, kışla ilgili oynanılmıştır. Makalede mevsimi oyun ve temaşalar genel olarak dört başlık altında tasnif edilmiştir: 1) Bağbozumu oyun ve temaşaları, 2) Bayram temizliği zamanı oyunları, 3) İlkbahar-Yaz mevsimi oyun ve temaşaları, 4) SonbaharKış mevsimi oyun ve temaşaları.
\end{abstract}

Anahtar Kelimeler: mevsim, oyun, temaşa, folklor, yağmur, rüzgar, bayram, temizlik.

\section{THE SEASONAL PLAYS AND SHOWS IN AZERBAIJAN AND ANATOLIA FOLKLORE}

\section{ABSTRACT}

The first perfect samples of the folk plays have been connected with different ceremonies, especially the seasonal ceremonies. In these plays that belonged to the economy, labor life and nature the people have been wished the abundance, praised the seasons and they have been met their coming with songs, dances and plays. Among the plays connected with the various believes, life styles and the labor activities, the seasonal plays have been played for executing some functions such as to cause to rain, to stop the rain, to call the sun, to incandesce the fire, to call the wind and to stop the wind. Scraping inscription on a stone and being the most ancient plays coming from the Turkic nation, and the dance elements and the signs of the ancient Turk believes of the "plays which in the inside of the dance" have been kept in these kinds of plays which have taken an important place in national dances, Turkish folk dances, various plays and shows.

The Seasonal plays have been played mainly in the harvest holiday, during the various holiday subbotniks and with the various seasons such as spring, summer, fall and winter. Also in the article the seasonal plays and the shows has been classified under four titels: 1) The harvest holidays and plays, 2) Holiday subbotnik plays, 3) Spring-summer plays and shows, 4) The plays and the shows of the fall-winter.

Keywords: season, play, show, folklore, rain, wind, holiday, subbotnik.

• AMEA Folklor İnstitutu, mmeleyke@gmail.com 
Doğa olayları karşısında çaresiz kalan insan için doğa ve doğa olayları sırlı ve mucizeli idi. Bunun için de eskiden insanlar karşılaştıkları mucizelerin sırrını çözmeğe, doğa güçlerine ve olaylarına hakim olmak veya onlardan yardım beklemek, arzu ve isteklerini ulaştırmak amacıyla çeşitli yöntemler kullanmışlar. Sözkonusu yöntemler sihir, ayin, ritüel şeklinde yapılarak zamanla ya merasimlere dönüşmüş, ya da çeşitli merasimler içinde kendine yer edinmiştir. Eskiden insanların inançları, doğa olaylarına karşı ilişkileri, hayat tarzı ve emek (iş) faaliyetleriyle alakadar olarak düzenlenmiş sözkonusu merasimler içinde mevsim merasimlerinin özel yeri vardır. Şöyle ki, halk oyunlarının kamil ilkin örnekleri ayrı ayrı merasimlerle, özellikle de mevsim merasimlerile ilgili olmuştur. Halk tarımcılık, çiftçilik hayatı ve doğayla ilgili olan bu oyunlarda her zaman bolluk arzulamış, mevsimleri övmüş, onların gelişini şarkılarla, danslarla, oyun ve temaşalarla karşılamıştır. Çeşitli inançlarla, hayat tarzı, emek faaliyetiyle ilgili oyunlar içinde mevsimi oyunlar yağmur yağdırmak, yağmuru kesmek, güneşi çağırmak, ateşi tutuşturmak, rüzgarı çağırmak, rüzgarı durdurmak gibi işlemleri yapmak için oynanılmıştır. Bu tip oyunlarda taş kitabelere kazınmış ve Türk halklarının bize gelip ulaşmış en eski oyunları olan, sonralar milli danslarda, halaylarda, çeşitli oyun ve temaşalarda kendine yer edinmiş "dansiçi oyunların" dans unsurları ve eski Türk inançlarının izleri günümüze kadar ulaşmıştır.

\section{Mevsimi Oyun ve Temaşalar}

Mevsimi oyunlar genellikle bağbozumunda, çeşitli bayram temizlikleri zamanı ve çeşitli mevsimlerle; ilkbahar, yaz, sonbahar, kışla ilgili oynanıldığı için onları aşağıdaki gibi tasnif edebiliriz:

1) Bağbozumu oyun ve temaşaları

2) Bayram temizliği zamanı oyunları

3) İlkbahar-Yaz mevsimi oyun ve temaşaları

4) Sonbahar-Kış mevsimi oyun ve temaşaları

\section{1) Bağbozumu Oyun ve Temaşaları}

Türk halkları hele eskiden genellikle yılın iki mevsimi - ilkbaharda baharın gelişi, emek mevsiminin başlanması ve sonbaharda bağbozumu zamanı dikilen ve toplanan mahsülün bol olması için törenler ve bayramlar yaparmışlar. Dedelerimizden bize gelip ulaşmış sözkonusu mevsimi bayramlardan biri de Bağbozumudur. Merasim şeklinde yapılan Bağbozumu şenliklerinde oyunlar önemli yer tutmaktadır. Bu oyunlar içerisinde Azerbaycan`ın çeşitli yörelerine (Şeki, Nahçivan, Kazak) has olan ritüel karakterli "Yel Dede" oyunu ilginçtir. Kendisinde bir çok ayin unsurları olan bu oyun büyük ihtimalle, ayin gibi ortaya çıkmış zamanla oyun şeklini alarak genellikle rüzgarı coşturmak ve sakinleştirmek amacıyla oynanılmıştır. Tahıl hasatı zamanı mahsülun temizlenmesi işlemini gerçekleştirmek için Yel dede yardıma çağrılır, gelmesi için çeşitli ezgiler, şarkılar söylenilir:

Yelli dedem, Yel dedem,

Telli dedem, Tel dedem...

Tahılımız yerde kaldı, 
Yahtamız elde kaldı.

A Yel dede, Yel dede,

Tez gel dede, gel dede.

Savur bizim hırmanı,

Atına ver samanı.

Den yığılıp dağ olsun,

Yel dedemiz sağ olsun. (Şeki Folkloru, 2009: 55)

Atalarımızın eski inamlarına göre, çağırdıkları Yel dede gelip harmanı savurur, samanını götürüp kendi atına verir, temizlenmiş tahıl ise, halka kalırdı. Hatta, aynı vakit şiddetli esen rüzgarı sakinleştirmek için annesinin ilki olan bir çocuğun eline elek verip şarkı söyleterdiler:

Külek, sürme at,

Gel, elekde yat!... (Şeki Folkloru, 2009: 55)

Azad Nebiyev in rüzgarla bağlı oyunlara örnek verdiği "Küleyi çağırma”, "Küleyi yatırma” (Nebiyev, 2009: 380-381), Nahçivan'da "Heyder" (Nahçivan Folkloru, 2010: 91-92) gibi oyunlar ayin karakterli "Yel Dede" oyununun varyantları niteliğindedir.

Azerbaycan halkının inancına göre, dünyadaki bütün rüzgarların yetkisi elinde olan mifoloji varlık Yel Dede'ye müracaat amacıyla oynanılan "Yel Dede" oyununda şamanizmin izleri görülmekdedir. Yel Dede ye müracaatla söylenen şarkılar, canlı bir varlık gibi yel ile, yani rüzgarla sohbet etmek, ondan yardım istemek, hatta rüzgar sert esdiği zaman onun gazaba geldiğini, sinirlendiğini düşünmek ve sakinleştirmek için ona kızlar tarafından Şeki yöresinde "Boğanak gelme, sene gelin olcam", yahut bir annenin ilki olan çocuğun şarkı söylemesi şamanistlerin doğa güçlerine karşı yaptıkları merasimlerdeki ayinlere, ritüellere benziyor. Aynı zamanda, Nahçivan yöresinde "Heyder" adıyla adlandırılan Yel Dede yi çağırmak amacıyla süpürge yandırıması şaman ritüellerinin temelini oluşturan sihir ve büyüleri hatırlatmaktadır.

Mahsül bayramı ile ilgili olarak çekirdeklerin dikilmesi, olgunlaşan tahılın toplanması, temizlenmesi süreçlerinin yer aldığı oyunlardan biri de çocuklar tarafından şarkılar söylenip danslar yaparak köylülerin tarım yaptıkları iş sürecinin taklidi olan "Tohum sepme" oyunudur (Şeki Folkloru, 2009: 403). Oyun zamanı yere çizilen daire çevresinde çocukların, köylülerin tarımla ilgili bütün faaliyetlerini, gördükleri işleri muzik eşliğinde göstermeğe çalışarak dans yapmasında dans içi oyunların unsurları kendisini göstermektedir. Aynı zamanda oyunda mahsül hasatından sonra köylülerin nasıl eğlendiklerini göstermek amacıyla onları taklid ederek çocukların oynaması, zamanında büyüklerin mahsül topladıktan sonra Mahsül bayramında yaptıkları merasim, şenlik ve oyunlardan haber vermektedir.

Azerbaycan`da eskiden iş mevsiminin bitmesi ile ilgili "Cıdır" yarışlarının yapılması, Mahsül bayramında ise, "Kendirbaz" temaşalarının gösterildiği malumdur (Nebiyev, 2009: 407, 430). 
Sovyet hakimiyeti yıllarında ise, Mahsül bayramı gösteri gibi yapııırdı. Her bir kolhoz, sovhoz ilçe merkezinde yük kamyonlarına dizdikleri şekil verilmiş mahsüllerini kolhozçuların katııımıyla, muzik takımlarının eşliğiyle izleyicilerin önünden gösteriler yaparak taşırlardı.

\section{2) Bayram Temizliği Zamanı Oynanılan Oyunlar}

Kitab-i Dede Korkut destanının "Dirse Han Oğlu Buğaç Han beyan eyler, hanım hey" boyunda Bayındır Hanın bir yaz, bir de güz boğayla buğrayı savaştırdığı bilinmektedir. Destanda ilkbaharda ve sonbaharda tasvir olunan bu tip eğlencelerin zamanında yapılan mevsim bayramlarına bir işare olduğu kanaatine gelmek mümkündür. Bildiğimiz gibi, mevsimi bayramlar genellikle ilkbaharda tarımın başlaması ve sonbaharda hasat ve bağbozumu zamanı ile ilgili olarak kutlanmaktadır. Şöyle ki, bayram öncesi evlerin, bahçelerin, tarım alanlarının temizlenmesi, düzenlenmesi ile bayram temizlikleri gerçekleştirilmiş olur. Bayram temizliği zamanı iş sürecini hafifletmek, görülen işleri daha istekli ve eğlenceli şekilde yapmak için çeşitli oyunlar oynanılır.

Belirtmek gerekir ki, eski tarihi olan temizlik zamanı oyunları Azerbaycan`da Sovyetler Birliği nin hakim olduğu bir devirde kendi güncelliğini muhafaza etmiştir. Bu oyunlar merkezi idareciliğe dayanan köy tarımcılık işlerinin yapılmasında, mevsimi mahsüllerin toplanması zamanı gerçekleştirilirdi. Buna pamuk, üzüm toplanması, ağac dikilmesi ve bu gibi faaliyetler dahildir. $\mathrm{Bu}$ imeciliklerde, yani toplu temizliklerde ahalinin toplu şekilde iş sürecine katılması çeşitli şenliklerin yapılmasını da zaruri kılmakta idi. Halk imeciliklerinde muzik takımları tarafından konsertler verilir, şarkılar söylenilir, çeşitli yarışlar düzenlenirdi. Söz adamları çalışan insanlarla görüşüp onların emeklerini değerlendiren şiirler okurdular. Yemek hazırlanıp paylanır, yemek için mola veren çalışanlar dans edip eylenerek işlerini hafifletirdiler. Bu türlü imecilik şenlikleri son zamanlarda daha çok Gah-Zakatala yöresine hasdır. Bundan başka, genellikle köy yerlerinde genç ailelere, yeni ev inşa edenlere yardım amacıyla da imecilikler yapılmaktadır. Bu zaman çeşitli tekerlemeler de söylenmektedir. Özellikle evin inşası zamanı ustaya taş, tuğla atanlar tekerlemeler söylerler. "Bir, iki, al geldi", yahut "bir, iki, usta al" tekerlemeleri ustanın dikkatini çekmek amacı taşımaktadır.

Zamanında Azerbaycan`ın bir çok yöresinde gündemde olan, imecikler zamanı oynanılan ve gösterilen bayram imecilik oyun ve temaşaları toplanmadığı için somut olarak her hangi bir örnek veremesek de, Anadolu`da bu tip oyunlara örnekler gerektiği kadar vardır. Bunun da esas sebepleri sözkonusu oyunların Anadolu'da "Köy seyirlik oyunları" adı altında toplanması ve hala da bir çok köylerde köylüler tarafından tarım, hasat, mahsül toplanması, bağbozumu, bayram imerclikleri ve bu gibi çeşitli zamanlarda eylence amacıyla gerçekleştirilmesiyle ilgilidir. Bu tür oyunlardan bir kısmı genellikle toplu halde yapılan hasat sonu imecliklerinde gösterilir. Böyle seyirlik oyunlara "Ekin kurtarma duası", "Ölü oyunu", "Yağmur duası" (Memmedova, 2014: 67) vb. örnek verilebilir. Hatta bazı seyirlik oyunlarının isimlerine bayram imecilikleri zamanı yapılan temizlik işleri yansımıştır. Böyle oyunlara Anadolu’nun Balıkesir yöresinde gösterilen "Ağaç budama" (Durmaz, 2012: 103), Koşapınar ve Bozcatepe köyünde gösterilen "Tezek toplama” (Düzgün, 1994: 163) temaşaları aittir. "Tezek toplama" temaşasının benzeri Anadolu`nun Tozkoparan köyünde "Çırpı toplama”, Gümüştepe 
köyünde "Madımak" (madımak yenilebilir bir bitkidir) gibi isimlerle bilinir (Düzgün, 1994: 164).

\section{3) İlkbahar-Yaz Mevsimi Oyun ve Temaşaları}

Halkımız çoğu zaman kışı insanlara mahrumiyetler getiren, onu aç ve soğukta bırakan, kısacası zorluklara salan kötü gücün simgesi, ilkbaharı ise bolluk, bereket sembolü gibi methetmişler. Bunun için de çoğu vakit kıştan kurtulup ilkbahara kavuşmayı bayram ederek çeşitli oyunlar oynayıp temaşalar göstermişler.

İlkbahar mevsimiyle ilgili oyun-temaşalara "Kosa Kosa" (Ağayev, Semedov, 2005: 21; El çelengi, 1983: 235-237), "Kosa gelin" (Heyet, 1990: 138), "Saya”, "Sayaçı" (Beydilli, 2003: 316-317), oyunlara "Godu Godu" (Nahçivan folkloru, 2010: 89; Azerbaycan folklor antolojisi, 2005: 31; Kafarlı, 2013: 29), "Yağmur gelini", "Çiğdem pilavı", “Telden Teleme” (Çelebi, 2007: 121-123), "Topkalak" (Azerbaycan folklor antolojisi, 2005: 150), "Diredöyme" (Memmedova, 2014: 68) vb. örnek verebiliriz.

Bugün hala Azerbaycan`da Nevruz bayramında oynanılarak Nevruz un esas sembollerinden birine çevrilen "Kosa Kosa" oyun ve temaşaları zamanında hem Azerbaycan`da, hem de Anadolu’da ilkbaharın gelişi, baharı karşılamak amacıyla oynanılırdı. Azerbaycan'da ve Anadolu'da çeşitli oyun ve temaşa varyantları olan "Kosa Kosa"daki "Kosa" kelimesinin çeşitli anlamları vardır. Kosa, Farsça bıyığı, sakalı çıkmayan adam anlamındadır. Bazı yörelerde, aynı zamanda masallarda da boyu kısa, akıllı, kurnaz kişi anlamına da gelir. Bu anlamı Azerbaycan ve Anadoludaki oyunlara uygun gelmektedir. Kös, sürünün önünde giden koyun ve teke anlamına geldiği gibi, aynı zamanda karvanın en önde giden hayvanın boğazına takılan çandır. Bazı yerlerde köse yeni evlenmiş kişi-güvey anlamındadır. Aynı zamanda Kastamonu köylerinde koç katımı ayındaki merasime Kösemi denir (And, 2012: 316). Sembolik olarak Kosa adı ile bağlanan ve eski yılın kovulması, yeni yılın gelişiyle alakalandırılan, Azerbaycan 'da "Kosa Kosa", Anadolu'da "Köse" adıyla gösterilen oyun ve temaşalarda Kosa'nın geyim kuşamındaki Gam-Şaman giyim simgeleri, danslarda, ölüp dirilme motiflerinde şamanizmin ve eski Türk inançlarının izleri vardır.

Azerbaycan`ın ve Anadolu’nun çeşidli yörelerinde ilkbaharda doğanın canlanması, koyunların kuzulaması ve mahsülun bolluğunu metheden "Saya", "Sayacı" oyunları oynanılır. Farklı anlamlar verilen "saya" ve "sayacı" kelimelerinin daha çok "say" sözünden ve koyunları saymakla ilgili olduğu düşüncesi mantığa daha yatkındır. Danslarla zengin olan arkaik tipli bu oyun bolluk bereket simgesi olup ritüel karakterlidir. Sayacılar tarafından kapı kapı gezerek "Sayacı nağmeleri" okuyup karşılığında yağ, peynir, un, buğda, prinç vb. alarak gösterilen "Saya oyunları"nda hayvanlara sevgi anlatılır, onların özellikleri tasvir edilir ve iyi, bol mahsüldarlık arzulanır. Biçim ve konu bakımından çeşitli olan sayacı tekerlemeleri ve şarkıları en çok da koyun ve keçiye itaf edilmiştir.

İlkbaharda "Saya" oyunlarından başka, baş çoban, soytarı, baş çobanın yardımcıları, teke oynadan, yalancı pehlivanlar, dansçılar, terekeme delikanlıları, benek, koyunlar, geçi, teke, geçi yavruları, genel sahne katılımcılarından oluşan "Selam Elik Say Beyler" (El Çelengi, 1983: 219-231) sayaçı temaşası gösterilirdi. Aynı zamanda halk arasında çok yaygınlaştığı için ata sözü gibi meşhur olmuş ve "Tenbel 
kardeş" adı ile de bilinen mülk sahibi, iki fakir kardeş, mülkedarın behre toplayanı, hizmetkarı, iki öküz ve cemaatten oluşan "Ekende yok, biçende yok, yiyende ortak kardeş" (El Çelengi, 1983: 231-235) adlı tarımcılıkla ilgili halk temaşası da gösterilirdi. Hatta bu temaşalarla saya oyunlarının sonbaharda ve kışda oynanıldığı gerçeğine halk edebiyatı kitablarında raslamak mümkündür.

İlkbaharda saya ve tarımcılıkla ilgili temaşalardan başka, at yarışlarının geçirildiği, at üzerinde çeşitli oyunların yapıldığı "Cıdır temaşaları"nın da ilkbaharın gelişiyle ilgili gösterildiği malumdur (Nebiyev, 2009: 407-413).

Illkbahar mevsiminde oynanılan mevsimi oyunlardan biri de "Godu Godu"dur. Azerbaycan'da ve Anadolu'da oynanılan bu oyun, genellikle yağmurlu günlerde gösterilir. Azerbaycanın çeşitli yörelerinde "Güdü Güdü", "Düdü Düdü”, "Gudu Gudu”, "Hodu Hodu", "Kos Kosa", Anadolu'da "Gode Gode", "Dode Dode" vb. adlarla oynanılan "Godu Godu" oyununun farklı varyantları da mevcuttur. Bu oyunun Azerbaycan ve Anadolu varyantları hem benzerdir, hem de farklıdır. Her iki bölgede oyun genellikle yağmurdan sonra oynanılması ve çeşitli eşyalar (kepçe, ağaç, dal, süpürge, korkuluk) süslenip kapı kapı gezdirilerek çeşitli varyantları olan "Godu Godu" tekerlemeleri söyleyip malzeme toplanması bakımından benzerdir. Önemli farklılık ise, oyunun Azerbaycan varyantlarının hepsinde yağmur çok yağdığı zaman güneşi çağırmak amacıyla, Anadolu varyantları ise, tam aksine yağmur yağdırmak için ya yağmurdan önce, ya da yağmurdan sonra oynanılır. Ahmet Caferoğlu, güneşi davet etmek için yapılan güneş duası geleneğinin sadece Anadolu’nun Trabzon ve Rize yöresine ait olduğunu belirtmektedir (Caferoğlu, 1994: 16)

Sözlüklerde anlamı "uzun süre yağan yağmurun dinmesi için süsleyip kapı kapı gezdirilen ayna ve kepçe" gibi verilmiş ve ister Nevruz bayramında, isterse de yağmurlar yağan zaman güneşi çağırmak amacıyla yapılan "Godu Godu" merasim ve oyunundaki "Godu" kelimesi güneşle ilgilidir. Bu kelimenin anlamı tam olarak anlaşılmasa da onunla ilgili çeşitli mülahazalar vardır. "Godu"nun ateşle bağlığı veya Farsça "Güneş tanrıçası" gibi "Huda" kelimesiyle ilgisi olduğu dününcelerini dikkate alacak olursak, bu kelimenin daha çok İngilizce Tanrı anlamında olan "God" kelimesi ile hem ses, hem de anlam bakımından ilgili olduğunu söyleyebiliriz.

Anadolu'da ilknahar mevsiminde "Godu Godu" oyunlarına benzer şekilde oynanılan oyunlara "Çiğdem Pilavı" ve "Telden Teleme"ni örnek verebiliriz. Yozgat ta oynanılan "Çiğdem Pilavı" martda ilk yeşeren çiğdemlerin haberini herkese vermek, "Telden Teleme" oyununda ise bitkilerden ilk yeşeren böğürtlenleri toplayıp diğer bitki, çalı ve ağaçları yeşilleşmeğe çağırmak için oynanılır (Çelebi, 2007: 121-123). Her iki oyunda kapı kapı gezerek tekerlemeler söyleyip insanlara baharın gelme müjdesi verilir.

İlkbaharda oynanılan oyunlardan biri "Topgalak oyunu"dur. Bu mevsimde hayvanların tüyü dökülende erkek çocukları dökülen tüyleri yerden toplayıp içine taş koyup küçük top yaparlar. Şeki-Zakatala yöresine has bu oyunun benzeri Nahçivan`da "Diredöyme oyunu" adıyla oynanılmaktadır. 5-6 erkek çocuğu tarafından oynanılan bu oyundaki top genellikle buğanın tüyünden yapılır. 
İlkbahar Yaz mevsimi kuraklık geçtiği zaman hem Azerbaycan`da, hem de Anadolu'da böyükler aynı amaç için yörelerimize göre farklı adlarla merasimler düzenleyerek çeşitli ayinler yapılır, sadaka verilir, her evden çeşitli malzemeler getirilir ve yörelere has farklı yemekler bişirilir. Çocuklar ise, yağmur yağması için çeşitli oyunlar oynarlar. Böyle oyunlara Azerbaycan`ın Şeki ve Zakatala yöresinde "Lailah" (Azerbaycan Folklor Antolojisi, 2005: 30), Nahçivan'da "Çömçe Hatun", "Yastan Zemiler", "Yağış Yağdırma", "Yağ Yağışım" (Nahçivan Folkloru, 2010: 88-91), Anadolu’da ise, "Yağmur Gelini”, "Kepçecik", "Çömçeli Gelin" ve "Süpürge Bezeme"ni (Çelebi, 2007: 121) örnek verebiliriz.

İlkbahar mevsimi oyunlarında güneşin davet edilmesi merasimi şamanların güneşle ilgili merasim ve inançlarının izlerini kendinde muhafaza etmiştir. Aynı zamanda İlkbahar-Yaz mevsimi oyunlarında oyuncuların kapı kapı götürdükleri eşyaları farklı biçimde süslemesinde ve ellerinde sopa ile dolaşmalarında şamanizmin unsurları kendisini göstermektedir. Hatta, baharda tarlaları, bağ bahçeni kuraklıktan kurtarmak için Oğuz terekemelerinin yağmur yağdırmak için Su tanrısına muracaatla suya "anne", göğe "dede", buluda "nine" demesinde de şamanizmin ve eski Türk inançlarının izlerine rastlanmaktadır. Bugün halk içinde böyüklerin ve çocukların Allah için "Allah dede" ifadesinin kullanılmasında da aynı inançların izleri yaşamaktadır. Şöyle ki, burada "Gök dede"nın yerini "Allah dede" almıştır.

\section{4) Sonbahar-Kış Mevsimi Oyun ve Temaşaları}

Kışta ilk kar yağışı günü halk onu bolluk sembolü gibi kabul edip şerefine merasim, şenlik yapıp silsile oyunlar oynamışlar. Çocuklar da kendi aralarında kışta dışarıda "Kar topu" oyunu oynamakla beraber, evde, özellikle köy yerlerinde odun şöminesinin çevresinde ısınırken oturmuş olarak ayaklarını uzadıp "Ayak oyunu" veya oyunda söylenen tekerlemenin adı ile "Su İç Kurtul" oyunu oynuyorlar (Memmedova, 2014: 72). Çeşitli varyantları olan ve oyunun da temelini oluşturan bu tekerlemenin farklı varyantlarına hem antolojilerde, hem halk edebiyatı kitaplarında karşılaşmaktayız. Nahçiva`nın Şerur, Ordubat yörelerinde oynanılan aynı oyunun benzer varyantına F.Köçerli nin Balalara Hediye kitabında tasviri verilen "Vur nağara, çık kırağa" oyununu (Kafarlı, 2013: 30-31) örnek gösterebiliriz.

Çocukların genellikle soğuk aylarda, karlı, yağmurlu, rüzgarlı havalarda evde oynadıkları oyunlardan biri de "Bel üste kimin eli" (Şeki Folkloru, 2009: 397-398) oyunudur. Bu oyunun bir diğer adının "Mezeli oyunu" olduğu dair bilgilere Resul Rza`nın tasvirini çok güzel verdiyi "Mezeli oyunu" adlı şiirinden ulaşmaktayız. Oyun yörelerimize göre çeşitli varyantları olan "Su iç kurtul" tekerlemesiyle başlayıp oyunun gelişimine göre de bir çok tekerlemelerle devam etmektedir. Oyunda belinin üzerine konan eli bulmak için "El üste kimin eli?" tekerlemesiyle cezalandırılan oyuncuya verilen hayvan adına uygun çeşitli tekerlemeler söylenir. Oyun tekerlemelerle zengin olduğu kadar hareketlerle de zengindir. Şöyle ki, oyuncuya sorulan "Ormanda sen ne gördün?" sorusuna cevap olarak ismini söylediği hayvanın hareketlerinin ve sesinin taklidi yapılır.

Çocukların severek oynadığı sonbahar-kış oyunlarından "Fındık" ve "Ceviz" oyunlarını örnek verebiliriz (Memmedova, 2014: 72). Bildiğimiz gibi, fındıkla cevizi toplama mevsimi sonbaharda olduğu için fındık ve cevizle oynanılan oyunlar genellikle 
sonbahar ve kış aylarına daha çok tesadüf edilmektedir. Araştırmalar zamanı her iki oyunun hem Azerbaycan, hem de Anadolu'da çeşitli varyantlarının mevcutluğu saptanmıştır. Azerbaycan`da "Fındık Fındık" (Şeki Folkloru, 2009: 407; Memmedova, 2014: 72) oyununun Ordubad ve Şeki varyantları birbirinden tamamen farklıdır, "Ceviz oyunu"nun ise, Şeki-Zakatala ve bir çok yörelerimize has "Kalakurma", "Yuvalama" (Yuvarlatma), "Aşık Goz" (Azerbaycan Folklor Antolojisi, 2005: 150-151) vb. çeşitlerini örnek verebiliriz.

Sonbahar-kış mevsiminde gösterilen ayin tipli merasim temaşalarından biri “Kevsec'tir (Ağayev, Semedov, 2005: 21-22). Bazı araştırmacılar bu temaşanın ilkbaharda, bazıları ise sonbaharda, soğuk günlerde gösterildiğini ileri sürmüşler. Temaşanın mazmunu ve mahiyetine baktığımız zaman sonbaharın sonu, kışın başlarında gösterildiği anlaşılmaktadır. Sıcak ve yağlı yemekler yedikten sonra katıra bindirilen adamın üzerine su ve kar dökülmesine rağmen adamın soğuğa aldırış etmeden "yandım yandım" demesi, yani halkın yaklaşmakta olan kışı korkutup ona karşı güçlü olduğunu göstermesinde şamanların maddi varlığa manevi etki göstererek istenilen sonuca ulaşma inamı kendisini göstermektedir.

Sonbahar-Kış mevsimi yağmurlu, soğuk, fırtınalı havalarda "Od Közertmek" oyunu oynanıldığı gibi "Maskara temaşaları" ve "Ferdi temaşalar" vb. meydan temaşaları da gösterilirdi (Seyidov, 1994: 379-340). Azad Nebiyev'in verdiği bilgilere göre genellikle "Maskara temaşaları" emek mevsiminden sonra genellikle sonbaharda başlayıp ilkbaharın başlarına kadar devam ederdi. Geniş alanlarda, küçük toplantılarda gösterilen bu temaşalar yallı ve danslarla, zurna ve balabanın eşliğinde, hazırcevap, gülmeli sözler, latifeler, rivayetler uydurup söyleyen, söz oynatan maskarabazlar tarafından gösterilirdi. Gülmekle ilgili olan maskara/masgara sözcüğü Avrupa halklarında, Yunanistan`da, İran`da olduğu gibi Azerbaycan`da da komedya, maskaracı, güldüren, eğlendiren, telhek, komediant ve mezhekeci, masğaraçı anlamındadır (Nebiyev, 2009: 432-436).

Maskara temaşalarından başka, "Ferdi temaşalar"ın da sonbahardan başlayarak yazın başlarına kadar, hatta bütün sene boyu devam ettiğini A.Nebiyev in verdiği bilgilerden öğrenmekteyiz (Nebiyev, 2009: 445-446).

İnsanların hayat tarzı, iş faaliyetleriyle ve doğada olan çeşitli olaylarla ilgili yapılan mevsimi oyunların bir çoğu ritüel karakterlidir. Ayin ve büyülerle zengin olan ve eski Türk inançlarının, şamanizmin izlerini taşıdığı ritüel, her hangi bir olaya göre biçimlenmiş davranışlar ve merasimler bütünüdür. Bireylerin toplumda yaşaması için terbiye olunmasında, bir araya gelerek sosyolojik ve kamusal bağların güçlenmesinde, halkın gelenek ve göreneklerinin, inançlarının yaşamasında oyun ve temaşaların temelini oluşturan ritüellerin rolü büyüktür.

Zengin kültüre sahip olan Türklerin yılın her mevsiminde oyunlar oynayıp gösteriler yaptığı araştırmalar zamanı makalede verilen somut örneklerle bir daha kesinleşmiştir. Bu çeşit köy seyirlik oyunlarının hem Azerbaycan, hem de Anadolu’nun farklı bölgelerinde oynanılması ve söz konusu oyunların bir çok yönden benzerliği aynı millet olarak benzer kültürün taşıyıcısı olmamızdan ve aynı düşünceye sahip olduğumuzdan kaynaklanmaktadır. 


\section{KAYNAKLAR}

AND M. (1976). "Komşu Kültürlerde Dramatik Köylü Oyunları ve Türk Etkisi” // Türk Folkloru Araştırmaları Yıllığı. Ankara, KB Mifad Yay., S.II, s.1-25

AND M. (2012). Oyun ve Bügü. İstanbul, 3.baskı, YKY Yayınları, 571s.

AĞAYEV E., Semedov Y. (2005) Ümumtehsil Mekteblerinde Halk Oyun Enenelerinden İstifade (Metodik Vesait). Bakı, Mütercim, $152 \mathrm{~s}$.

Azerbaycan Folkloru Antologiyası. (2010). Nahçıvan fokloru. I cild / Toplayıb tertib edenler M.Ceferli, R.Babayev. Nahçıvan, Ecemi, $512 \mathrm{~s}$.

Azerbaycan Folkloru Antologiyası. (2009). IV kitab. Şeki folkloru. I cild / Tertib edenler H.Ebdülhelimov, R.Gafarlı, O.Eliyev, V.Aslan. Bakı, Seda, 490 s.

Azerbaycan Folkloru Antologiyası. (2005). XIII kitab. Şeki, Gebele, Oğuz, Gah, Zakatala, Balaken folkloru / Tertibçiler İ.Abbaslı, O.Oliyev, M.Abdullayeva. Bakı, Seda, $550 \mathrm{~s}$.

Balıkesir Köy Seyirlik Oyunları Üzerine Bir İnceleme. (2012). Yüksek Lisans Tezi, Hazırlayan: Uğur Durmaz, Danışman: Halil İbrahim Şahin. Balıkesir, $171 \mathrm{~s}$.

BEYDILLİ C. (2003) Türk mifoloji sözlüyü. Bakı, Elm, 418 s.

CAFEROĞLU A. (1994), Kuzey Doğu İllerimiz Ağızlarından Toplamalar, TDK

yayınları 116, Ankara, 2.b. s.XVI

ÇELEBİ D.B. (2007). Türkiye ve Azerbaycan`daki Çocuk Oyunları ve Oyuncaklarının Karşılaştırmalı İncelemesi // Yüksek lisans tezi. Muğla: Muğla Üniversitesi, 294s.

El Çelengi. (1983). Toplayıb tertib edenleri T.Ferzeliyev, İ.Abbasov. Bakı: Genclik, 388

Erzurum Köy Seyirlik Oyunları. (1994). Doktora Tezi, Hazırlayan: Dilaver Düzgün, Tez Yöneticisi: Bilge Seyidoğlu. Erzurum, $238 \mathrm{~s}$.

HEYET C. (1990). Azerbaycan Şifahi Halk Edebiyyatı. Bakı, Azernəşr, 165 s.

KAFARLI R. (2013). Uşak Folklorunun Janr Sistemi ve Poetikası. Bakı, Elm ve tehsil, $540 \mathrm{~s}$.

MEMMEDOVA M. (2014). Azerbaycan ve Anadolu Folklorunda Halk Oyun ve Temaşaları. Bakı, Elm ve Tehsil, $208 \mathrm{~s}$.

NEBIYYEV A. (2009). Azerbaycan Halk Edebiyyatı. I kitab. Bakı, Çırak, 640 s.

SEYIDOV M. (1994). Gam-Şaman ve Onun Kaynaklarına Ümumi Bakış. Bakı, Genclik, 282 s. 